\title{
Identifying Stressors and Coping Strategies of Elite Esports Competitors
}

Matthew J. Smith, University of Winchester, Winchester, UK

Phil D.J. Birch, University of Chichester, Chichester, UK

Dave Bright, University of Chichester, Chichester, UK

\begin{abstract}
Researchers have examined some of the psychological aspects of competing at a high level in esports. The present study aims to build on this literature by examining the various stressors faced and the associated coping strategies employed by seven esports competitors. The interviews were inductively analysed, and the findings illustrated a range of internal (e.g., communication issues, lack of shared team goals) and external (e.g., event audience, media interviews) stressors that the participants faced. Following this, the coping strategies used to deal with these stressors were deductively analysed. A number of emotion- (e.g., breathing, relaxation), problem- (e.g., intra-team communication after matches), and approach- (e.g., team camps, delegating roles) coping strategies were described by participants. Avoidance coping strategies were predominantly highlighted as being used during games. Results are considered in line with how applied practitioners might support players to develop strategies to deal with stressors, which might in turn lead to performance enhancements.
\end{abstract}

\section{KEYWORDS}

Communication, Competition Environment, Coping Strategies, Counter-Strike Go, Demands, Mental Skills, Optimal Performance, Performance Psychology, Sport Psychology

\section{INTRODUCTION}

The video game industry has seen a dramatic acceleration in growth over the last 10 years (Himmelstein et al., 2017). Globally, more and more viewers are watching esports, and international businesses and organisations have invested millions of dollars into sponsoring competitions (Jenny et al., 2017). This has led to the formulation of professional teams, with some competing for seven-figure prize funds and playing contracts. Similar to traditional sports (e.g., soccer, basketball), many young video gamers are attracted to the prospect of earning millions of dollars and therefore aspire to be high-level professional gamers. The rise of professional video gaming has resulted in esports. Morris (2013) defined esports as "organized video game competitions that pit world class players against each other for cash prizes" (Gamers Are Not Only Athletes, para. 2). The games are either played remotely online with the team members in various locations, or more commonly in high level competition, the teams gather at a specific event location to compete. Such competitive gameplay 
has developed to include highly-paid star-players, team-owners, spectators, and increasing levels of sponsorship (Taylor, 2012). Furthermore, competing in such a high-pressured environment has led to greater interest in the mental side of esports. For example, Andrejkovics (2016) in writing about the mindset of winning players and teams in esports, suggests that up to 50 per cent of improvement in performance is linked to mental preparedness and a player's state of mind.

In line with the increase in competitive gaming, the interest into the science underpinning performance has accelerated dramatically in the last decade. However, there have been relatively few empirical studies which have explicitly examined the factors influencing esports performance when compared to studies examining traditional sports. For example, research which has examined esports performance has focused on expertise (Fanfarelli, 2018) and mental skills usage (Himmelstein et al., 2017). Very recently, key stakeholders in esports (e.g., ESL) have expressed an interest into the stressors faced by esports athletes and the strategies used to overcome stress. However, research has yet to explicitly examine stressors faced by esports athletes and the coping strategies used to overcome such stressors. Therefore, the purpose of the present study is to enhance our understanding of such stressors and coping strategies in the esports environment.

The term stressor has been used to express "environmental demands encountered by individuals" (Fletcher et al., 2006). As esports athletes are competing in highly pressurized and competitive environments that are comparable to more traditional sports, it is likely that stressors exist in an esports performance environment. Research has identified that elite athletes are under intense pressure to succeed and face a wide variety of demands in performing in an elite environment (e.g., Thelwell et al., 2007; Weston et al., 2009; Arnold \& Fletcher, 2012). Researchers have investigated these demands principally using qualitative methods to interview elite participants about the specific stressors they face when performing. For example, Cosh and Tully (2015) interviewed 20 Australian University athletes to understand the stressors they faced combining elite sport participation with higher education study. The findings revealed a range of stressors that included schedule clashes, financial pressure, and inflexibility of coaches. Himmelstein et al. (2017) interviewed five high-level League of Legends players about psychosocial factors in competitive esports and found that a number of obstacles prevented optimal performance. These obstacles included pressure of competing, being harassed by others, and negative communication during performance. However, no research has explicitly examined stressors that esports players face.

An ability to deal with the demands of elite performance environments has been identified as a key element needed for sporting excellence (cf. Fletcher \& Arnold, 2017). In addition, if athletes are unable to cope with demands, researchers have offered evidence of negative outcomes for individuals such as burnout (Goodger et al., 2007). Consequently, researchers have also investigated how athletes cope with the demands of competing in such environments. Lazarus and Folkman (1984) define coping as deliberate cognitive and behavioural efforts to manage specific external and/or internal demands that are appraised as stressful. Research attention has centred on illustrating coping strategies in different elite contexts, for example, the coping of professional cricketers (Thelwell et al., 2007), youth swimmers (Hayward et al., 2017) and elite student athletes (Cosh \& Tully, 2015). Findings have illustrated a range of coping strategies, with athletes employing multiple strategies to deal with single stressors (Nicholls \& Polman, 2007). This research has informed approaches that applied practitioners might use to support athletes. However, thus far, there is a dearth of research that has considered coping strategies used by esports competitors.

Research studies investigating coping have seen such coping strategies categorized into five primary dimensions. Initially, Lazarus and Folkman (1984) proposed two dimensions of coping; problem-focussed coping, which are strategies that aim to manage and/or alter the stressor at hand (e.g., attempts to manage the person/stressor transaction, goal setting, problem solving, time management, and information gathering); and emotion-focussed, referring to regulation of the emotional distress resulting from demands but do not attempt to change the actual stressor. (e.g., attempts to regulate emotional states, deep breathing, visualisation, and acceptance). Other researchers have proposed a 
further three coping dimensions; avoidance coping, which includes both behavioural (e.g., removing self from the situation) and psychological (e.g., cognitive distancing) efforts to disengage from a stressful situation; approach coping, which involves confronting the source of stress and deliberately attempting to reduce it (e.g., taking direct action, increasing effort, and planning); and appraisalfocused coping, which involves the (cognitive) re-evaluation of a situation to reduce its importance and refers to strategies such as situation re-structuring (for a review of these coping dimensions, see Nicholls \& Polman, 2007).

\section{Performance Psychology}

In an effort to gain a performance edge over their competitors, esports teams have started to recruit a host of support staff (e.g., coaches, managers, strategists). The desire to win lucrative competitions has naturally led to an increased demand in performance enhancing strategies. Specifically, esports teams are now recruiting sports psychologists to help them deal with the psychological demands of training and competition. The most high profile recruitment of a sports psychologist was in 2016 by Counter-Strike: Global Offensive (CSGO) team Astralis. Prior to 2016, Astralis were considered one of the best CSGO teams on the planet. However, key stakeholders in esports suggested that Astralis' lack of ability to cope with high pressure competitive environments prevented them from winning their first major tournament. In January 2017, Astralis won the ELEAGUE Major and members of the team attributed the victory to their developed sense of composure when competing in the later stages of major tournaments. The anecdotal evidence presented provides a compelling argument for the use of sports psychology and specifically coping strategies in esports. However, as previously discussed, there is a distinct lack of evidence which has examined stressors and coping strategies in esports. Research examining stressors and coping strategies would not only provide a fruitful insight into the psychology underpinning esports, but it would also enable practitioners to develop evidencebased interventions aimed to enhance performance.

In summary, given that esports players are competing in increasingly pressurized environments, and stress is likely to negatively impact on performance in such an environment, the aim of the present study was to develop and enhance an understanding of stressors that esports participants face. Furthermore, in his review of the stress and coping literature in sport, Nicholls (2016) highlights an inability to cope effectively with stressors can result in a range of negative outcomes for the individual. Thus, the second aim of the study was to enhance an understanding of the coping strategies that esports players employ to deal with such stressors. From an applied perspective, it is hoped that the findings of the current study will add to the currently limited body of research that has examined high performance environments in competitive esports. Indeed, we hope the study not only serves to inform practitioners about how to best support esports players to help improve performance, but also to facilitate the personal development of players.

\section{METHOD}

\section{Design}

To extend an understanding of the stressors that esports players experience and coping strategies players use to deal with these stressors, qualitative methods were used in this present study. This explorative approach uses interviews to prompt participants to provide in-depth information about stressors and coping strategies that captures the subjective meaning of esports players in contextual situations (Kvale \& Brinkmann, 2008). Furthermore, such a method allows a consideration of the different interpretations of participants, in order to generate rich data from various perspectives. Interviews were therefore selected to explore the experiences of players who have competed in a high-level esports competition environment. 


\section{Participants and Competition Event}

A purposeful sampling method was used, with specific sampling criteria established a priori, which allowed recruitment of participants who could provide the most valuable responses to address the research aims. The first criterion was to recruit high level competitive esports players. Second, participants were recruited who had recently participated in a competitive event, to enable them to reflect on specific events and thus provide detailed information concerning the stressors they faced in such an environment. Thus, participants were recruited from four teams that competed in an in-person CSGO competition. Specifically, the ESL Premiership CSGO Spring finals, the most prestigious national tournament in the UK.

Participants were seven male esports players $\left(M_{\text {age }} 20.57, S D=2.07\right.$ years $)$ who represented three of the four sides competing at the ESL Premiership CSGO Spring finals. Participants had between two and six years of experience playing competitive esports $(M=3.43, S D=1.37$ years) and had played for their current CSGO team for between three and 14 months $(M=7.9$, $S D=3.1$ months). Six participants reported themselves to be of white-British and one reported being of White-European ethnicity.

\section{Procedure}

Following institutional ethical approval, contact was made with organizers from ESL to attend an esports event with the purpose of recruiting participants to the study. The lead researcher, who previously had little knowledge of esports, attended the competition weekend, which enhanced the research process in a number of specific ways. This included developing his understanding of the competitive structure of CSGO, terminology used (e.g., the names of the maps used in the competition and indeed how the use of each map was decided for each match) and some of the competitive strategies used. This understanding was valuable for building rapport with the competitors, both during the weekend, and then subsequently when the interviews were conducted (Sève et al., 2006). Conversations with the competitors allowed the researcher to build rapport, to explain the purpose of the research being conducted, and then to ask if they were willing to be contacted and to be interviewed as part of the study. These competitors provided contact details in order for the researcher to contact them after the competition to arrange an interview.

The researcher closely observed the players in their competitive environment and also made notes while the competition was in play, which were subsequently used to develop the interview guide by allowing the researcher to 'prompt' the participant with specific information. Following the weekend, the lead researcher contacted participants and conducted seven interviews by Skype, which ranged in duration from 34 to $62 \mathrm{~min}\left(M_{\text {minutes }}=52.28\right)$. All interviews took place between one and three weeks after the tournament took place. The Skype recordings allowed each interview to be transcribed verbatim for use with data analysis.

\section{Interview Guide}

A semi-structured interview guide was developed for this study which created a consistent approach to the interviews, while allowing some flexibility to explore specific issues (Patton, 2002). Questions in the interview guide were developed after reviewing previous qualitative research that has explored stressors and coping (e.g., Thelwell et al., 2007; Weston et al., 2009). Following reminders regarding confidentiality and some introductory questions, the main part of the interview involved exploring the stressors participants face, both during the competition weekend and overall in their competitive involvement in esports. Prompt and probe questions were used to encourage participants to expand on examples of stressors raised to elicit more thorough information, using specific examples from the competition weekend where it was necessary. In the second part of the interview, participants were asked about their coping strategies to deal with the challenges of playing competitive esports. This was principally stimulated by the examples of stress that participants identified earlier in the interview. 
For example, "you said that one element that affected you when competing in CSGO was... can you tell me how you might cope with this?". Elaboration questions (e.g., "could you explain further what you did when you [used coping strategy]?") were used to encourage more detailed responses to explain coping strategies used.

\section{Data Analysis}

The first stage of the analysis involved the first and second authors immersing themselves in the transcripts and extracting raw-data quotes, collating segments of text which illustrated either stressors or coping strategies. In line with the analysis strategy used in previous research (e.g., Weston et al., 2009; Thelwell et al., 2010), the stressors and coping strategies were each analysed separately. The stressors were analysed using inductive processes, with the first and second authors independently coding the raw-data quotes which were then organized into lower- and higher-order themes. Where discrepancies between the researchers emerged, further discussions took place until consensus was reached on coding the stressors. The coping strategies were deductively coded, with the first and second authors independently coding the raw-data quotes into one of the five established dimensions of coping outlined in the introduction (i.e., emotion-focussed coping, problem-focussed coping, approach coping, avoidance coping, and appraisal coping). The final stage of analyses of both the stressors and coping strategies involved discussion with the third author who acted as a "critical friend" (Smith \& McGannon, 2017). His role was to challenge the placement of raw data themes into the higher order categories, in order to reach a consensus.

\section{RESULTS}

The results are presented in two main sections. First, data is presented illustrating the stressors faced by participants. Second, coping strategies used in response to these stressors are presented.

\section{Stressors Faced by Esports Participants}

51 raw data themes were identified in the interview transcripts, each representing a stressor that participants identified. These were organized into 13 lower order themes and 4 higher order themes. A further classification was made by organizing the stressors into two general dimensions (internal and external stressors). This hierarchical organisation of data is presented in Figure 1. In the following section, rich illustrative quotes are presented to allow the reader to gain a greater understanding of the stressors experienced.

\section{Internal Stressors}

This general dimension was divided into two higher-order themes, namely team issues and individual issues. Team issues encompassed six lower-order themes including team communication, criticism from teammates and in-game leaders (IGLs), and not sharing team goals. Individual issues comprised of two lower-order themes; life balance and lifestyle impacts.

\section{Team Issues}

\section{Communication Issues}

One participant highlighted the importance of communication with team esports environments, saying, "I think communication is huge, it's one of the biggest things, because obviously information needs to be fed around the map well". Various communication issues were identified as stressors, such as players not listening or following instructions, and at times, a simple lack of communication during gameplay. For example, one participant spoke about players within the side not listening to instructions and the problems this caused; "Sometimes they just like do their own thing, it is really annoying... you're thinking 'well, they're just not gonna listen, so what's the point?'” 
Figure 1. Stressors reported by esport competitors

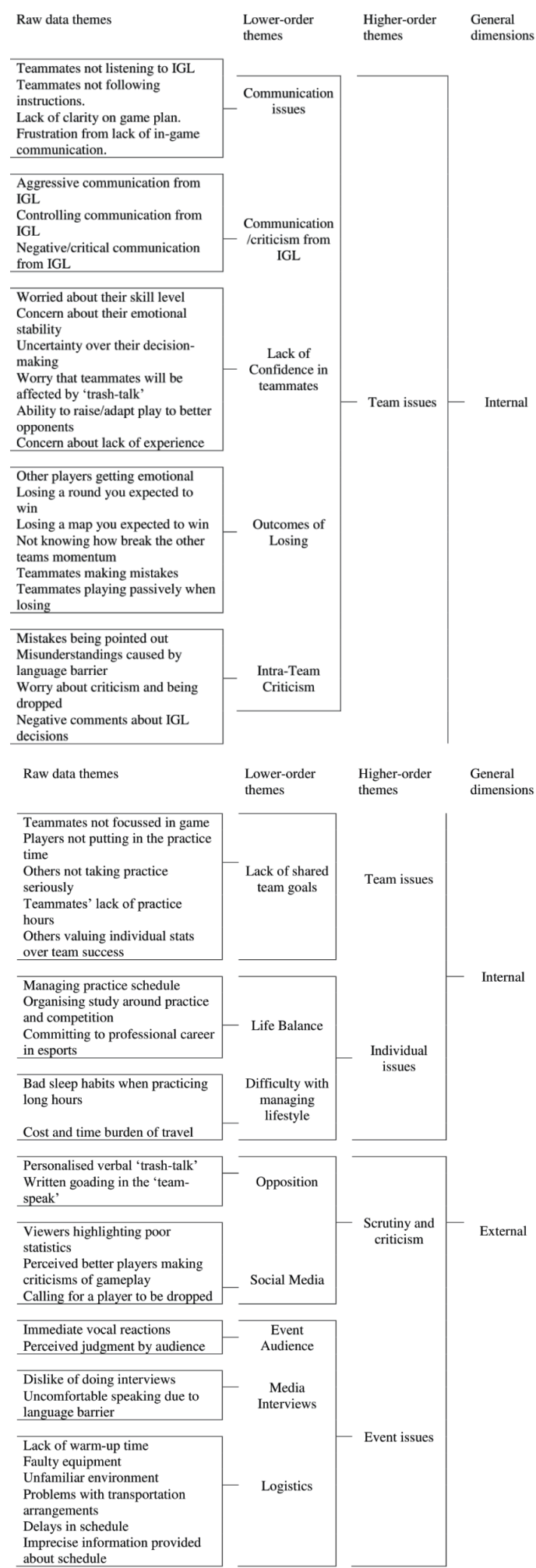




\section{Communication/Criticism From In-Game Leader (IGL)}

Specific stressors resulted from the way their IGL spoke to them. For example, one participant spoke about the aggressive verbal criticism they had received from a previous IGL. This participant reflected on constantly being told how bad they were by the IGL, and how they should find someone better to replace the participant. This participant reflected that "his way of motivating players is to destroy them. He said to me "you are so stupid, and so dumb, and so incapable of doing anything that once you go into the real world, you'll find it too difficult." To reinforce this point, another participant recalled:

I was very micro-managed by the leader and if you died somewhere before they'd told you to make a move then, you'd get screamed at, like literally screamed at down the microphone, calling people on the team shit, and say like 'you're stupid.'

\section{Lack of Confidence in Teammates}

Participants identified stressors concerning certain aspects about their teammates approach when competing. These included issues with worrying over a lack of skill level and their decision-making abilities. A further example was given by one participant concerning the lack of emotional control that some teammates showed hindering team progress; "The emotional part of the team is what I'm scared of. . . if the emotions are taking over, and like, they're 'oh I can't do this, I'm bad' then everything will just fall apart".

\section{Outcomes of Losing}

The participants identified stressors that occurred during competition when their team were losing. For example, one player spoke about the challenges of being behind in a game, saying, "People are scared to take some aggressive plays. . . mentally it's very hard when you're down". Another participant spoke about being behind and the other team having momentum within a specific map (i.e., they have won a few rounds in a row) and illustrated the negative impact on the team's play:

Everything we were doing just wasn't working, it's kinda hard to come back... we lost so many rounds in a row, rounds we shouldn't have been losing, just making awful mistakes. We were just tilting... no one wanted to take control because no one had the confidence. It was just like a knock on effect.

\section{Intra-Team Criticism}

Participants highlighted the stressors caused by teammates criticizing each other. One participant highlighted the stressor from mistakes and subsequent criticism they received from other players in their team; "I always had anxiety when I played, so, each mistake, I wouldn't wanna make plays because if I failed, I knew I was gonna get shouted at and raged at and my spot on the team was on a knife's edge". Another participant (an IGL) spoke about the additional demands of managing such team dynamics, referring to the 'very negative way' the player offered the criticism and how the player receiving the criticism was 'instantly on the defensive'. Interestingly, one participant offered his insight into why certain players find it challenging to receive criticism; "Some people have never been involved in team aspects before. . . they don't understand that they are working in a unit, like they're working as a team". Indeed, another participant reflected by saying "I think to be able to take criticism is a huge skill", and this aspect of players not being able to accept criticism appeared to be a common finding in the data.

\section{Lack of Shared Team Goals}

Participants expressed specific frustrations with others in their team not sharing a similar attitude or approach. For example, a reoccurring pattern in the data was seen regarding approaches to practice, 
with one participant saying his team often lacked a professional approach to practice, with too much joking around. Another participant illustrated how they felt the rest of the team did not share his desire to practice:

It's about getting 5 people who actually want to play as well... we're not playing practice as a team, but people are just not playing individually like, people just haven't turned Counter-Strike on for like 5 days... we should be playing, and staying crisp and, bringing new ideas to the next practices.

Another stressor resulted from a participant perceiving a teammate to overly focus on his own stats. This participant reflected how this teammate will refer to himself as the 'star player' and how this is detrimental as such players "play for themselves in game to get better stats".

A further player reflected on the unfairness of a teammate receiving the most recognition, with other players doing more of the unseen work which was not as obvious on published stats. Interestingly, one player reflected on why he felt this specific aspect of working in teams might be holding UK teams back in performing on an even higher, international level:

That's why the Europeans are so much better, people sacrifice more for their teammates... here they don't understand that when they're sacrificing for their teammate another teammate is sacrificing for them.

\section{Individual Issues}

\section{Life Balance (Working Towards a Professional Career)}

In this sub-theme, stressors represented striking a balance between practicing and competing at a high-level in esports, and life outside of esports. For example, participants outlined aspects concerning the actual decision to work towards a professional career and the associated financial and social implications of this. With one participant (a student) saying:

I go out now and again, only now the lifestyle is more just finishing my deadlines and playing Counter Strike... I'm a little bit older now. When I used to play at the beginning, I was just going out all the time, probably it affected my gameplay a lot.

Difficulties With Managing Lifestyle

Participants raised aspects such as the cost and time commitments of travelling to live competitions. Participants also spoke about the demands of having a practice schedule which needed to fit in around their primary job and its associated challenges (e.g., having a consistent amount of sleep):

When you're working and you come home it's kinda hard 'cos, you are getting a kinda bad sleeping pattern... you don't use the time to actually kinda work out or try to do something productive when you have the free time.

\section{External Stressors}

This general dimension was divided into two higher-order themes. The first was stressors surrounding external scrutiny and criticism, which had two lower-order themes (i.e., from opposition, and on social media). The second higher-order theme comprised of stressors caused by the competition event organisation, which had three lower-order themes (i.e., audience, media interviews, and logistics). 


\section{Scrutiny and Criticism}

\section{From Opposition}

Participants spoke about dealing with goading from opposition players during gameplay. This was seen to take two forms, first in terms of the words that opposition players might write in the 'team-speak', and second, in the verbal utterances made by the opposition. One participant illustrated this:

When you've lost a round, you can hear the other team shouting through the microphone, 'cos it's not completely noise cancelling... sometimes, 'cos I've got like a personal rivalry with one of their players I could hear him shouting my name.

\section{Criticism in Social Media}

One participant illustrated comments on social media for a teammate to be dropped; "they are pushing him down "cos they're saying "yeah, you should bring in someone else, you should do this, you should do that". One participant highlighted criticism of their stats on how this person did not appreciate the players role; "I get some shit sometimes on Twitter and from people saying that I have bad stats and stuff because, but they don't understand what I do in this team".

\section{Event Issues}

One participant highlighted the stressor of dealing with having a live audience watching and reacting instantly to the play:

Like, you have wiffed, you have no idea if the camera's on you or anything, but in your head they've just watched that and your, it just makes you feel so much worse. . you look up and people just don't look impressed or they're just like (sucking noise).

Live events are regularly streamed on the internet, and the production can include player interviews, for example, straight after a game has finished. One player highlighted how a teammate found such interviews challenging; "He's not that confident doing interviews "cos obviously it can be a bit nerve wracking especially when English isn't you're first language”.

\section{Logistics}

Participants identified a variety of stressors linked with the organisation of competitive events, such as not being able to warm-up properly. One participant recalled; "We just got to the stage and we had to set up, and we had to play within like 15 minutes, so we didn't do anything to get that bit of practice in before the game started". Another participant reinforced how the change in the schedule caused a stressor:

We got told it was going start at 4 o'clock and then, we were still at the hotel at like 2:30, and we were coming back to get there for 3 so we could warm up for an hour. Because the other game finished early, we got "ah, you're starting at 3 now", so we literally had to go straight into the game without, sort of preparing at all.

\section{Live Audience}

Another participant highlighted stressors caused by organizing flights to live events: 
Flights get booked days before I leave, everything is very last minute, everything's very rushed, and because of that it's not as professional as, you know with, with more professional examples as like, Sky Sports, or HBO, Showtime for example. And the way those are run and the way those are treated.

One participant further commented on the challenge of competing live and dealing with a new environment:

When you're playing on a new stage which you've never played on before, you've gotta try new computers, peripherals, but you've got new monitors and, all this kinda stuff... also mentally coming onto the stage.

\section{Coping Strategies}

The analyses resulted in 35 raw data themes representing the participants' coping strategies. The coping strategies were deductively organized into the five forms of coping identified in previous literature which were emotion-focussed coping, problem-focussed coping, approach coping, avoidance coping, appraisal coping. These themes are illustrated in Figure 2.

\section{Emotion-Focused Coping}

These strategies refer to overt behavioural strategies that regulate the emotional distress resulting from demands (Nicholls et al., 2010), but do not attempt to change the actual stressor. A range of strategies were identified to deal with the immediate stress of the situation. For example, one participant described simply taking a break between maps; "We went out for a quick smoke break, and just like, just to get outside, get some fresh air". Participants also spoke about adjusting their focus, particularly when they are playing live competitions:

You look to your teammates when you're speaking to them, and just try and pretend that you're at home... Just zone out, and just focus on the game... and the cameras, if you're focused enough on the game, you can kind of just block them out.

A number of coping strategies identified by participants appeared to negatively impact their well-being. Such maladaptive strategies included smoking, comfort eating, and even vomiting, which one participant described; "So it got to the point where I couldn't eat anymore. My parents got really worried about me because I stopped eating. Then before every single official match I just started vomiting". Additionally, participants described other strategies that could have negative impacts, such as venting when a result was going against them.

\section{Problem-Focused Coping}

These refer to short-term or immediate strategies to manage and/or alter the stressor at hand. Participants illustrated communication strategies, for example, speaking to a teammate who was lacking confidence after losing a game, or positive communication from teammates and the IGL when the team are losing:

[The IGL] says it quite a lot that at the end of the day the games not over until that round hits 16 so it doesn't matter if they're 10 nil up or 5 nil up if we just keep on grinding away in the round then, then you can get back into it.

Another player illustrated talking about things openly and honestly, but after the game finished: 
Figure 2. Coping strategies illustrated by competitive esport players

Raw data Themes

\begin{tabular}{l|} 
Comfort eating \\
Not-eating/vomiting \\
Exercise \\
Smoking \\
Relaxation - listening to music \\
Venting on teammates \\
Adjusting focus on game \\
Taking a break \\
Muting the microphone \\
Counting to ten \\
Internalising frustration
\end{tabular}

Communicating with teammates

Discussing issues in a calm manner

Finding solutions to problems

Reflecting on the tone of conversations

Pausing in games to allow discussion and find solutions

\begin{tabular}{l} 
Organising/taking part in team boot camps \\
Taking on a team coach \\
Non game related group activities \\
Delegating roles to reduce stress \\
Making use of online demos/videos \\
Being consistent and reliable in-game \\
\hline
\end{tabular}

Not listening to teammates pre-match
Not playing aggressively, to not make a mistake
Leaving the team
Not discussing mistakes in-play with team
Not reading social media
Not engaging with social media debates
Not doing interviews
Not shaking hands with opponents (who have wound them
up)
up)

\footnotetext{
Re-framing comments from teammates Appraising and evaluating the meaning behind game statistics

Considering importance of own role within team

Evaluating losses (e.g., against better teams)

Appraising reasons for online criticism
}

Higher-order themes

Emotion focussed coping

Problem focused coping

Approach coping

Avoidance coping

Appraisal coping

If we won or lost, we'd always go outside, get everyone away from the computer, sit in a circle and talk about what's going wrong, all look each other in the face... and talk about if there's something that might go onto the next map.

\section{Avoidance Coping}

These include both behavioural (e.g., removing self from the situation) and psychological (e.g., cognitive distancing) efforts to disengage from a stressful situation (Krohne, 1993). Participants described numerous ways they dealt with stressful situations by avoiding them, such as avoiding doing interviews which made them uncomfortable, not shaking hands with opponents who had wound them up, and ultimately, leaving a team that they did not enjoyed working with. Participants spoke in more depth about dealing with the stressor of criticism in social media, for example, this participant spoke about staying out of issues that are debated in social media; "I try to stay out of the drama a bit but, when 
people lose especially people can get very frustrated and tweet and they can sometimes type in the in-game chat as well".

Participants also spoke about using avoidance strategies to deal with in-game situations which appeared to be maladaptive as they might directly have a negative impact on performance. For example, when players recalled struggling in a game situation, a coping strategy appeared to be playing in a more passive manner to avoid making mistakes:

If you start playing scared you don't wanna give up your frag, you don't wanna die, you don't want to make a mistake. . just playing really passively and not really going for anything and not playing how you would usually play.

Another avoidance strategy was refraining from discussing difficult matters (e.g., criticizing a teammate, offering suggestions on how to do things better), particularly during a game. Such problem-focussed strategies are also a form of avoidance, with one participant reflecting on steering clear of within-game discussions; 'you can't do that, because then everyone would just start arguing and it would just put everyone off completely, you just can't do that." Another participant reinforced this by explaining how arguments had led to his team avoiding having such discussions in the game:

You need to sort of fix the problem while it's happening. So I think you can't really push it until after the game because you need to win the game at the end of the day, and if you can talk about it... But a lot of time in the team it turns into an argument so it's hard to bring it up during the game.

\section{Approach Coping}

These referred to longer-term, orchestrated strategies that involved confronting the source of stress and deliberately attempting to reduce it (strategies include taking direct action, increasing effort, and planning; Roth \& Cohen, 1986). Such strategies included organizing and taking parts in 'boot camps', to live and train together for a period of time. This allowed the players to "just be together as a team" and build a sense of teamness; "when we're in the house together we have to all be there, and we're all playing and we're going out together for food and, we're chilling together". One of the participants who was also an in-game leader spoke about delegating roles to reduce stress, or giving players specific roles to boost confidence. A further example referred to when performance is going badly, with a participant speaking about making use of online demos and videos as a training aid:

I watch it and see if someone dies, what does this other player do on the other side of the map? Like how does he react to that information? Like, what does he do? Does he go aggressive? Does the whole team go aggressive? Does he rotate to a different side?

\section{Appraisal-Focused Coping}

This coping involves the (cognitive) re-evaluation of a situation to reduce its importance and refers to strategies such as situation re-structuring (e.g., re-evaluation; Cox \& Ferguson, 1991). For example, one participant re-framed information provided by statistical information; "it's a team game, and looking at stats doesn't really reflect on the context and how the game went. You can have someone who was, who was helping the team out in other ways". Another participant re-evaluated reasons for severe online criticism, saying, "they're just the guys who want be in your position" and how writers are motivated to criticise to gain recognition themselves. Another participant reflected on how they evaluate criticism in a more positive way, driving him to improve further: 
I'm taking it better now, I'm just taking it from an objective stance, to just improve rather than take it as a kind of emotional thing, when it's not really like that... and just tried to fix it, personally, because everyone wants to improve and everyone wants to be better in the team so it's what you need to do.

\section{DISCUSSION}

This research adds to a growing body of literature that has examined stress and coping in a competitive environment, through enhancing an understanding of the stressors faced and coping strategies adopted by high-level esports players. In the current study, a variety of internal and external stressors were identified. Internal stressors produced the largest number of lower order themes, with the most pertinent theme being team issues (e.g., in-game communication, criticism, lack of confidence). For example, communication was cited by several players as an important and impactful element within esports, with the data illustrating stressors resulting from a lack of communication (including intra-team communication not being listened to) or aggressive and critical communications from both the IGL and teammates. Lack of effective communication and the resulting lack of teamwork impacts negatively on performance in esports (Himmelstein et al., 2017), and whilst the IGL was stated to be the root of many of the negative communication issues it has previously been suggested that a hierarchal relationship within sport can be a stressor for both parties (Frey, 2007). Therefore, a reciprocal pattern is likely, whereby the aggressive behaviour of the IGL causes the reduction in the players desire to follow instructions seen within the data, which in turn, causes the IGL to react more aggressively.

Intra-team criticism was also identified by participants as a major stressor, causing anxiety for some players either because they think they will receive further criticism or potentially be dropped from the team. While intra-team criticism is often found in sport (Paradis, Carron, \& Martin, 2014), the reason it becomes a stressor within esports seems to be a product of both the ineffective way in which criticism is given, and a lack of ability within some players to take more helpfully framed criticism in the constructive way it is intended. This appears to lead to criticism being perceived as personal, emotional, or confrontational (Sullivan \& Feltz, 2003). This is amplified by a willingness of players to overtly critique other members of their team during play. Such criticism seems to be somewhat accepted as a norm within the sport, suggesting also that players lack an ability to accept criticism from teammates, however constructive.

External stressors included goading from the opposing team (via either comments written on screen within game or overheard trash talk) and similar behaviours from fans on social media. Whilst they take different forms, both sources tend to focus on the skill level of the players, something also perceived by the players to be a source of criticism from audiences when playing live events. Stressors caused by such public scrutiny support the findings from Thelwell and colleagues (2007) who found scrutiny from the public and media to be stressors in a sample of elite cricketers. Other external stressors included the logistics of working to a schedule that is dictated by the organizing body and is at the mercy of technology, leading to disruption in elements such as warm-up time. This supports the findings of Cosh and Tully (2015) who found dealing with scheduling problems to be a key stressor for elite student athletes.

In considering coping strategies, our findings illustrate that participants used a variety of coping strategies to deal with stressors. In line with previous literature, emotion-focused and problem-focused coping strategies were frequently employed (Lazarus \& Folkman, 1984). Specifically, adjusting focus was a highly adopted strategy participants used to regulate emotion in the competition environment. For instance, participants used strategies (e.g., listening to music, counting to 10,) to "zone out" and "block out" irrelevant stimuli (e.g., cameras). Research has supported these findings in that athletes use emotion-focused strategies (e.g., Weston et al., 2009) to maintain focus on salient stimuli in an effort to maximise performance. However, the findings highlight how these emotion-focused strategies were employed before and after performances as opposed to whilst performing. Participants 
also cited using a number of problem-focused and avoidance-focused coping strategies to deal with stressors associated with communication. A key finding from this study is the apparent use of positive self-talk by both players and IGLs to deal with losses. In terms of employing avoidance strategies in the form of discussing strategies and approaches after the game, this may be beneficial in the short-term, to avoid negative emotions that might result from perceiving such communication as criticism. However, it is likely that avoiding in-game communication is not an effective long-term strategy as such communication is vital to promote problem-solving during the game and ultimately improve performance. For instance, a season-long examination of stress and coping strategies of elite adolescent swimmers identified that avoidance coping had negative impacts on both performance and overall well-being (McDonough et al., 2013). Indeed, many participants discussed issues with in-game communication, specifically concerning aggressively presented feedback and/or issues with teammates being able to receive criticism. Given the evidence supporting the positive outcomes associated with effective communication in esports (e.g., well-being, effort, and performance; Himmelstein et al., 2017), it could be argued that key stakeholders in esports would benefit from communication training.

The findings from this study provide preliminary evidence that the identified stressors pose significant challenges to the esports athletes in this study. The evidence indicates that despite the players in this study using a range of coping strategies, there is an overuse of avoidance strategies during competitive play, and a lack of effective problem- and emotion-focussed strategies used during gameplay. Given that research (e.g., Hatzigeorgiadis \& Galanis, 2017) has provided support for the efficacy of psychological skills training in maintaining focus during sports performance, it is intuitive to argue that esports athletes could benefit from psychological skills training, to arm them with strategies (e.g., positive self-talk, breathing techniques, imagery to improve focus) to use during competitions to regulate emotions. Applied practitioners are encouraged to assess current psychological skills usage of esports athletes and align training to the specific demands of the competitive environment. In addition, the findings highlight in-game communication is a stressor for players, and it appears that developing communication between team-members would benefit performance. It could be argued that the athletes in this study would benefit from receiving communication training to allow them to better deal with critical feedback from teammates. Applied practitioners are encouraged to work with esports teams to build trust and respect in a psychologically safe environment, allowing constructive feedback and opinions to be given without the fear of consequences (Nembhard \& Edmondson, 2012).

One limitation of this study was that only male participants were sampled. This was due to all the competitors in the four teams being male, and thus, there was no option to interview female participants. Indeed, the environment at the competition was male-dominated, with only a small number of women employed (one as an interviewer, one on the hospitality team, and one in the production team). It is likely that there are additional stressors that female gamers face. For example, Ruvalvcaba, Shultze, Kim, Berzenski, and Otten (2018) examined comments that spectators directed toward female and male gamers, and found that in comparison, females experienced a greater degree of sexual harassment. In addition, the innate levels of the participants' stable coping styles were not considered, as players may be affected by stressors to different levels depending on such traits. A final consideration concerning the sample is that two IGLs were interviewed. Research has examined stressors of cricket captains (Smith, Arnold, \& Thelwell, 2017) and found that such players who take on a playing and leadership role (as an IGL does) experience additional stressors due to this dual role.

The preliminary evidence presented in this study could lead to a number of fruitful research avenues. First, in light of the applied suggestions concerning the need to improve communication, future research is warranted to examine the impact of communication and psychological skills training on performance and well-being of esports athletes. Second, to address the lack of research examining female participants, future research might focus on the challenges that women face in the esport environment. Third, future research might investigate in more depth how personality might affect the ability to cope. Indeed, Kaiseler, Polman, and Nicholls (2011) have highlighted other personality dimensions (e.g., neuroticism and extraversion) which may impact on coping, and such 
findings could more fully inform applied practitioners as to which players might require enhanced psychological support to cope with stressors. Finally, in light of the additional stressors that IGLs face, future research might focus more on understanding such specific stressors in an effort to support IGLs in performing their role optimally.

In summary, the present study provides a unique examination of the stressors faced by competitive esports players and associated coping strategies. It is proposed that the current study has naturalistic generalizability, which refers to the findings resonating with the reader's personal experiences (Smith, 2018). The extent to which the study has naturalistic generalizability therefore depends on the experiences of those reading the research. While the findings are directly generalizable to CSGO players, findings can be generalizable to a broader range of esports players who are likely to recognise similarities and differences with the findings in terms of being familiar with such competitive environments. Smith (2018) also suggests that researchers should provide readers with suitable evidence (through the richness of data presented) to allow readers to reflect upon these to allow the audience to make connections to their own lives and experiences. By providing in-depth quotes to illustrate stressors and coping strategies in the results, the findings should resonate with a broader range of esports athletes beyond CSGO players. It is also hoped that the findings will inform applied practitioners concerning stressors faced by esports players, and provides suggestions for practitioners working with players helping them to develop effective coping strategies. 


\section{REFERENCES}

Andrejkovics, Z. (2016). The Invisible Game: MINDSET of A Winning Team. Scotts Valley, CA, USA: CreateSpace.

Arnold, R., \& Fletcher, D. (2012). A research synthesis and taxonomic classification of the organizational stressors encountered by sport performers. Journal of Sport \& Exercise Psychology, 34(3), 397-429. doi:10.1123/ jsep.34.3.397 PMID:22691400

Cosh, S., \& Tully, P. J. (2015). Stressors, coping, and support mechanisms for student athletes combining elite sport and tertiary education: Implications for practice. The Sport Psychologist, 29(2), 120-133. doi:10.1123/ tsp.2014-0102

Cox, T., \& Ferguson, E. (1991). Individual differences, stress and coping. In C. L. Cooper \& R. Payne (Eds.), Wiley series on studies in occupational stress. Personality and stress: Individual differences in the stress process (pp. 7-30). Oxford, England: John Wiley \& Sons.

Fanfarelli, J. R. (2018). Expertise in professional Overwatch play. International Journal of Gaming and ComputerMediated Simulations, 10(1), 1-22. doi:10.4018/IJGCMS.2018010101

Fletcher, D., \& Arnold, R. (2017). Stress in sport: The role of the organizational environment. In C. R. D. Wagstaff (Ed.), The organizational psychology of sport: Key issues and practical applications (pp. 83-100). New York: Routledge/Taylor \& Francis Group.

Fletcher, D., Hanton, S., \& Mellalieu, S. D. (2006). An organisational stress review: Conceptual and theoretical issues in competitive sport. In S. Hanton \& S. D. Mellalieu (Eds.), Literature reviews in sport psychology (pp. 321-374). New York: Nova Science.

Frey, M. (2007). College coaches' experience with stress - "problems solvers" have problems too. The Sport Psychologist, 21(1), 38-57. doi:10.1123/tsp.21.1.38

Goodger, K., Gorely, T., Lavallee, D., \& Harwood, C. (2007). Burnout in sport: A systematic review. The Sport Psychologist, 21(2), 127-151. doi:10.1123/tsp.21.2.127

Hatzigeorgiadis, A., \& Galanis, E. (2017). Self-talk effectiveness and attention. Current Opinion in Psychology, 16, 138-142. Doi: org/10.1016/j.copsyc.2017.05.014

Hayward, F. P., Knight, C. J., \& Mellalieu, S. D. (2017). A longitudinal examination of stressors, appraisals, and coping in youth swimming. Psychology of Sport and Exercise, 29, 56-68. doi:10.1016/j.psychsport.2016.12.002

Himmelstein, D., Liu, Y., \& Shapiro, J. L. (2017). An exploration of mental skills among competitive league of legend players. Journal International Journal of Gaming and Computer-Mediated Simulations, 9(2), 1-21. doi:10.4018/IJGCMS.2017040101

Jenny, S. E., Manning, R. D., Keiper, M. C., \& Olrich, T. W. (2017). Virtual (ly) athletes: where eSports fit within the definition of "Sport". Quest, 69(1), 1-18. doi:10.1080/00336297.2016.1144517

Kaiseler, M., Polman, R. C. J., \& Nicholls, A. R. (2011). Effects of the Big Five personality dimensions on appraisal coping, and coping effectiveness in sport. European Journal of Sport Science, 12(1), 1-11. doi:10.1 080/17461391.2010.551410

Krohne, H. W. (1993). Vigilance and cognitive avoidance as concepts in coping research. In H. W. Krohne (Ed.), Attention and avoidance: Strategies in coping with aversiveness (pp. 19-50). Ashland, OH: Hogrefe \& Huber Publishers.

Kvale, S., \& Brinkmann, S. (2008). Interviews: Learning the craft of qualitative research interviewing. Sage Publications.

Lazarus, R. S., \& Folkman, S. (1984). Stress, appraisal, and coping. New York: Springer.

McDonough, M. H., Hadd, V., Crocker, P. R., Holt, N. L., Tamminen, K. A., \& Schonert-Reichl, K. (2013). Stress and coping among adolescents across a competitive swim season. The Sport Psychologist, 27(2), 143155. doi:.10.1123/tsp.27.2.143 
Morris, K. (2013, December 21). Gamers are not only athletes, but the internet has changed the definition of 'sports'. Wired. Retrieved from https://www.wired.com/2013/12/are-esports-really-sports-who-cares-its-hereto-stay/

Nicholls, A. R. (2016). Adaption, stress and coping in sport. In R. J. Schinke, K. R. McGannon, \& B. Smith (Eds.), Routledge international handbook of sport psychology. Abingdon, UK: Routledge.

Nicholls, A. R., \& Polman, R. C. J. (2007). Stressors, coping, and coping effectiveness among players from the England under-18 rugby union team. Journal of Sport Behavior, 30(2), 199-218.

Paradis, K. F., Carron, A. V., \& Martin, L. J. (2014). Athlete perceptions of intra-group conflict in sport teams. Sport \& Exercise Psychology Review, 10(3), 4-18.

Patton, M. Q. (2002). Qualitative research \& evaluation methods. California: Sage Publications.

Pollio, H. R., Henley, T. B., \& Thompson, C. J. (1997). The Phenomenology of Everyday Life. Cambridge: Cambridge University Press. doi:10.1017/CBO9780511752919

Roth, S., \& Cohen, L. J. (1986). Approach, Avoidance, and Coping with Stress. The American Psychologist, 41(7), 813-819. doi:10.1037/0003-066X.41.7.813 PMID:3740641

Ruvalcaba, O., Shulze, J., Kim, A., Berzenski, S. R., \& Otten, M. P. (2018). Women's experiences in esports: Gendered differences in peer and spectator feedback during competitive video game play. Journal of Sport and Social Issues, 42(4), 295-311. doi:10.1177/0193723518773287

Seve, C., Poizat, G., Saury, J., \& Durand, M. (2006). A Grounded Theory of Elite Male Table Tennis Players' Activity during Matches. The Sport Psychologist, 20(1), 58-73. doi:10.1123/tsp.20.1.58

Smith, B. (2018). Generalizability in qualitative research: Misunderstandings, opportunities and recommendations for the sport and exercise sciences. Qualitative Research in Sport, Exercise and Health, 10(1), 137-149. doi:1 $0.1080 / 2159676 X .2017 .1393221$

Smith, B., \& McGannon, K. R. (2018). Developing rigor in qualitative research: Problems and opportunities within sport and exercise psychology. International Review of Sport and Exercise Psychology, 11(1), 101-121. doi:10.1080/1750984X.2017.1317357

Smith, M. J., Arnold, R., \& Thelwell, R. C. (2018). "There's no place to hide": Exploring the stressors encountered by elite cricket captains. Journal of Applied Sport Psychology, 30(2), 150-170. doi:10.1080/10413200.2017. 1349845

Sullivan, P. J., \& Feltz, D. L. (2003). The preliminary development of the Scale for Effective Communication in Team Sports (SECTS). Journal of Applied Sport Psychology, 33(8), 1693-1715. doi:10.1111/j.1559-1816.2003. tb01970.x

Taylor, T. L. (2012). Raising the stakes: e-sports and the professionalization of computer gaming. MIT Press. doi:10.7551/mitpress/8624.001.0001

Thelwell, R. C., Weston, N. J. V., \& Greenlees, I. A. (2007). Batting on a sticky wicket: Identifying sources of stress and associated coping strategies for professional cricket batsmen. Psychology of Sport and Exercise, 8(2), 219-232. doi:10.1016/j.psychsport.2006.04.002

Thelwell, R. C., Weston, N. J. V., \& Greenlees, I. A. (2010). Coping with stressors in elite sport: A coach perspective. European Journal of Sport Science, 10(4), 243-253. doi:10.1080/17461390903353390

Weston, N. J. V., Thelwell, R. C., Bond, S., \& Hutchings, N. V. (2009). Stress and coping in single-handed roundthe-world ocean sailing. Journal of Applied Sport Psychology, 21(4), 460-474. doi:10.1080/10413200903232607 
Matt Smith received an MSc in Applied Sport and Exercise Psychology at Bangor University in 2006, and a $P h D$ in Sport Psychology at the University of Chichester in 2009. He worked as a senior lecturer in sport and exercise psychology at the University of Chichester, before moving to the University of Winchester in 2018. He writes and presents on issues concerning the social psychology of sport, including leadership, group processes, and stress and coping.

Phil Birch received a BSc in Sport and Exercise Science and an MSc in Sport and Exercise Psychology at the University of Chichester in 2006 and 2007, respectively. Phil completed his PhD in Sport Psychology at the University of Chichester in 2014. He has worked as a senior lecturer in sport and exercise psychology at the University of Chichester since 2014. He writes and presents on issues concerning performance psychology, including mental toughness and think-aloud protocols.

Dave Bright has been an active martial arts student and coach for more than two decades, and received a BSc (Hons) in Sports Coaching Science in 2013, and followed this up with an MSc in Psychology of Sport and Exercise in 2014, both from the University of Chichester. He has remained at Chichester as a senior lecturer in sports coaching, and is currently in the early stages of $P h D$ study. His research interests lie in the application of skill acquisition literature to real world coaching scenarios, as well as coach education, specifically in the world of traditional martial arts. 